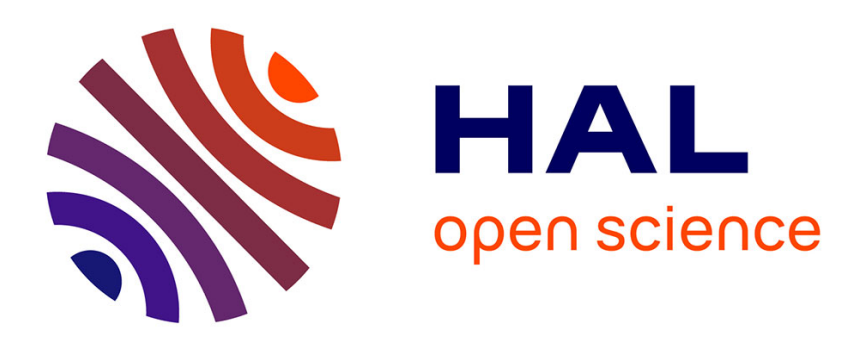

\title{
Dynamic Yield Strength of a Zirconium Base Metallic Glass
}

\author{
C. Cline, L. Jacobson, J. Reaugh
}

\section{To cite this version:}

C. Cline, L. Jacobson, J. Reaugh. Dynamic Yield Strength of a Zirconium Base Metallic Glass. Journal de Physique IV Proceedings, 1997, 07 (C3), pp.C3-493-C3-498. 10.1051/jp4:1997385 . jpa-00255542

\section{HAL Id: jpa-00255542 https://hal.science/jpa-00255542}

Submitted on 1 Jan 1997

HAL is a multi-disciplinary open access archive for the deposit and dissemination of scientific research documents, whether they are published or not. The documents may come from teaching and research institutions in France or abroad, or from public or private research centers.
L'archive ouverte pluridisciplinaire HAL, est destinée au dépôt et à la diffusion de documents scientifiques de niveau recherche, publiés ou non, émanant des établissements d'enseignement et de recherche français ou étrangers, des laboratoires publics ou privés. 


\title{
Dynamic Yield Strength of a Zirconium Base Metallic Glass
}

\author{
C.F. Cline, L. Jacobson* and J.E. Reaugh \\ Physics and Space Technology Directorate, Lawrence Livermore National Laboratory, \\ Livermore CA 94550, U.S.A. \\ *Los Alamos National Laboratory, Los Alamos New Mexico 87545, U.S.A.
}

\begin{abstract}
Taylor anvil tests in the reverse ballistic mode have been carried out to determine the dynamic yield strength of a $\mathrm{Zr} 62.6$ w/o $\mathrm{Cu} 13.23, \mathrm{Ti} 11.01, \mathrm{Ni} 9.77$, and Be 3.38 metallic glass. Scanning electron microscopy has been utilized to evaluate the details of the rod and anvil interface after impact. Computer simulations have also been carried out to interpret and confirm the results and conclusions.

Résumé. Le test de TAYLOR par la méthode de balistique inverse a été utilisé pour déterminer la résistance dynamique d'un verre métallique de $\mathrm{Zr} 62.6 \%-\mathrm{Cu} 13.23 \%-\mathrm{Ti} 11.01 \%-\mathrm{Ni} 9.77 \%$ et Be 3.38\%. La microscopie électronique á balayage a été utilisée pour examiner l'interface entre la cible et le barreau aprés impact. Des simulations numériques ont été effectuées pour interpréter et confirmer les résultats et les conclusions.
\end{abstract}

\section{BACKGROUND}

The G. I. Taylor [1] dynamic compression test consists of firing a cylinder of material at an essentially rigid target and deducing the dynamic yield stress from measurements made on the recovered projectile.

Wilkins and Guinan [2] showed that the simple theory accounted reasonably well for the dependence of the final length of projectiles on impact velocity and flow stress for a variety of real materials.

They [2] demonstrated the validity of the relationship

$$
\frac{\mathrm{L}_{\mathrm{f}}}{\mathrm{L}_{0}}=\exp \left(-\frac{\rho_{0} \mathrm{u}_{0}^{2}}{2 \mathrm{Y}_{0}}\right)
$$

over a wide range of velocities where $L_{f}=$ final length of projectile, $L_{0}=$ initial length, $\rho_{0}=$ density of the projectile, $\mathrm{u}_{0}=$ the projectile impact velocity and $\mathrm{Y}_{0}=$ the dynamic yield strength of the projectile.

The results indicated that a simple test of a penetrator material existed wherein the measurements of initial and final length and the impact velocity on a rigid target allows the experimenter to easily obtain the dynamic yield strength.

One of the authors has long been interested in a class of materials called "metallic glasses" which have theoretical strengths [3]. A model system to study is the metallic glass $\mathrm{Zr} 62.6 \mathrm{w} / \mathrm{o} \mathrm{Cu} \mathrm{13.23,} \mathrm{Ti} \mathrm{11.01,} \mathrm{Ni}$ 9.77, and Be 3.38 which can be prepared in large ingots (see Table 1 for Physical Properties).

\section{EXPERIMENTAL PROCEDURES AND RESULTS}

Rods of the $\mathrm{Zr}$ base metallic glass were prepared from the melt. The rod material was examined by X-ray diffraction and determined to be amorphous. The rod was ground to size and samples cut to length using a diamond saw (see Figures 1,2).

The "reverse ballistic" experimental set up was similar to the one used by Wilkins [2] but the zirconium glass rod was held in position using a styrofoam fixture and the $A D-95 \mathrm{Al}_{2} \mathrm{O}_{3}$ projectile fired from our smoothbore gun at $0.0274 \mathrm{~cm} / \mathrm{ms}$. The $\mathrm{Al}_{2} \mathrm{O}_{3}$ punch was $2.2 \mathrm{~cm}$ in diameter. The initial and final measurements on the rod were $\mathrm{L}_{0}=1.28 \mathrm{~cm}, \mathrm{D}_{0}=0.306 \mathrm{~cm}, \mathrm{~L}_{\mathrm{f}}=1.03 \mathrm{~cm}$. 
The recovered $\mathrm{Zr}$ metallic glass rod was measured by micrometer along its length for changes in diameter near the impact end. It was noted that the rod was straight and we observed very little mushrooming or bulging.

Microscopic pictures were taken of the rod end and the target. The observation of the target and rod was that the rod reached temperatures of the order of the glass transition temperature $\left(\operatorname{Tg}=623^{\circ} \mathrm{K}\right)$.

The measured initial and final length numbers result in a dynamic yield strength of $.0133 \mathrm{Mb}$ (as a lower limit). The value was calculated using the relationship

$$
\mathrm{Y}_{0}=-\frac{\rho_{0} \mathrm{u}_{0}^{2}}{2 \ln \mathrm{L}_{\mathrm{f}} / \mathrm{L}_{0}}
$$

where $\rho_{0}=6.11 \mathrm{gm} / \mathrm{cm}^{3}$. This number is quite different than the value expected from the microhardness at room temperature. The hardness $H$ is $598 \mathrm{~kg} / \mathrm{mm}^{2}$, and using the relationship of $H / 3=Y_{0}$ we expected to obtain about $20 \mathrm{~kb}$ as the strength. This assumes a room temperature strength was dominant as has been observed for polycrystalline metals, but the observations indicate that the impact interface was molten.

\section{COMPUTER SIMULATIONS AND ANALYSIS}

We developed a material description for performing computer simulations of the Taylor impact test using the HEMP simulation program. The measured elastic properties are density $6.11 \mathrm{~g} / \mathrm{cm}^{3}$, bulk modulus 112 $\mathrm{GPa}$, and shear modulus $37.2 \mathrm{GPa}$. At an impact velocity of $200 \mathrm{~m} / \mathrm{s}$, which was the highest velocity we simulated, we estimate the shock stress to be about $5 \mathrm{GPa}$, so that the effect of non-linear compressibility will be small. We used the flow stress model described by Steinberg, Cochran and Guinan [4] to incorporate thermal softening. We ignored pressure hardening and work hardening. Since the measured Knoop hardness was 600 , we used a yield strength of $2 \mathrm{GPa}$. The measured glass-transition temperature is $623 \mathrm{~K}$. which we take to be the temperature at which the strength is zero. We used the atomic composition to estimate the specific heat to be $0.33 \mathrm{~J} / \mathrm{g} / \mathrm{K}$, although the reported Debye temperature of this material, 327 $\mathrm{K}$, suggests that the actual value may be somewhat lower than the ideal value of $3 \mathrm{R}$ that we used.

We performed simulations of the Taylor impact of a rod with $2 \mathrm{~mm}$ diameter and $9.6 \mathrm{~mm}$ long at velocity of 100,150 , and $200 \mathrm{~m} / \mathrm{s}$ (see Table II). At the lowest velocity, the rod is stopped before significant mett occurs. As a consequence, the rod exhibits the usual diametrical expansion on the impacted end. At the two higher velocities, severe strain localization and melting occurs at the impact face. At the highest velocity simulated, the rod exhibits both a melt zone and a region of diametrical growth.

In Taylor's analysis of the anvil test [1] Equations 1-3 are completed by a momentum balance across the plastic front that ignores lateral inertia in the plastic zone, $h$.

$$
\begin{gathered}
\frac{\mathrm{dh}}{\mathrm{dt}}=\mathrm{v} \\
\frac{\mathrm{dx}}{\mathrm{dt}}=-(\mathrm{u}+\mathrm{v}) \\
\frac{\mathrm{du}}{\mathrm{dt}}=-\frac{Y_{0}}{\rho_{0} \mathrm{x}}
\end{gathered}
$$

Following Guinan's analysis, [5] however, we complete the set by equating the instantaneous loss of kinetic energy from the rigid shank $(x)$ to the plastic work done across the plastic front

$$
\frac{\mathrm{d}}{\mathrm{dt}}\left(\frac{1}{2} \rho \mathrm{xu}^{2}\right)=\mathrm{W} \frac{\mathrm{dx}}{\mathrm{dt}}
$$

where $\mathrm{W}$ is the plastic work per unit volume, and is a function of the plastic strain, $\varepsilon$. Eq. (4) can be rearranged using (1-3) to form

$$
\frac{\rho_{0} \mathrm{u}^{2}}{2 \mathrm{Y}_{0}}=\frac{\mathrm{W}(\varepsilon)}{\mathrm{Y}_{0}}+\frac{\mathrm{v}}{\mathrm{u}+\mathrm{v}}-1
$$

where the plastic strain $\varepsilon$ is given by 


$$
\varepsilon=-\ln \frac{\mathrm{v}}{\mathrm{u}+\mathrm{v}} .
$$

For the simplest case of constant yield stress $Y_{0}$, the Equations (1-3) and (5) can be solved parametrically for the final length $\mathrm{L}_{\mathrm{f}}$

$$
\begin{gathered}
\frac{\mathrm{L}_{\mathrm{f}}}{\mathrm{L}_{0}}=\mathrm{p}_{0}\left(1-\ln \mathrm{p}_{0}\right) \\
\frac{\rho_{0} \mathrm{U}_{0}^{2}}{2 \mathrm{Y}_{0}}=\mathrm{p}_{0}-\ln \mathrm{p}_{0}-1
\end{gathered}
$$

in terms of the initial value of the parameter $p$ introduced by Taylor, where

$$
p=\frac{v}{u+v},
$$

and $\mathrm{p}-1$ is the instantaneous engineering strain across the plastic front.

The solution for the final length is in excellent agreement [5] with HEMP simulations of Taylor anvil tests of materials with constant flow stress $Y_{0}$, for the range

$$
0 \leq \frac{\rho_{0} \mathrm{u}_{0}^{2}}{2 \mathrm{Y}_{0}} \leq 2 .
$$

Here, we wish to use this method of solution to examine the case where thermal softening plays a significant role. The simplest model for the reduction of the flow stress, $Y$, due to heating from plastic work was described in [6] for behavior at high strain rates. It utilizes a linear decrease in strength with energy density. (The model in [6] gives the reduction in strength as a linear function of temperature rise, but also assumes a constant specific heat up to the melt temperature). For this case,

$$
\mathrm{Y}=\mathrm{Y}_{0}\left(1-\frac{\mathrm{W}}{\mathrm{Y}_{0} \varepsilon_{1}}\right) .
$$

and we define $\varepsilon_{1}$ to be the ratio of the maximum plastic work to the initial flow stress.

The plastic work, then is defined by

$$
\frac{\mathrm{dW}}{\mathrm{d} \varepsilon}=\mathrm{Y}_{0}\left(1-\frac{\mathrm{W}}{\mathrm{Y}_{0} \varepsilon_{1}}\right)
$$

and solved as

$$
\mathrm{W}(\varepsilon)=\mathrm{Y}_{0} \varepsilon_{1}\left(1-\varepsilon^{-\varepsilon \varepsilon_{1}}\right),
$$

which specializes Equation (5) to be

$$
\frac{\rho_{0} \mathrm{u}^{2}}{2 \mathrm{Y}_{0}}=\varepsilon_{1}\left(1-\mathrm{p}^{\frac{1}{\varepsilon_{1}}}\right)+\mathrm{p}-1 .
$$

If we consider the right hand side of 13 , it has a maximum value of $\left(\varepsilon_{1}-1\right)$ for $\varepsilon_{1}>1$ at $p=0$. If $\varepsilon_{1} \leq 1$, then the right hand side is never positive. From this, we infer that if $\varepsilon_{1} \leq 1$, then the material is unable to absorb the kinetic energy of the rod by plastic work at any velocity. The shank of the rod is decellerated by the initial flow stress $Y_{0}$, but the heating from plastic work is sufficient to reduce the strength significantly (we will imprecisely refer to this as "melt"), which leaves decelerated projectile shorter, with less mass, and without a flared end from the impact.

If $\varepsilon_{1}>1$, then for this material there is a critical velocity $u_{1}$,

$$
u_{1}=\left(2 Y_{0}\left(\varepsilon_{1}-1\right) / \rho_{0}\right)^{1 / 2}
$$

Below this velocity, the material behaves normally, although with reduced strength. The rod will have its initial mass and a deformed impact end. With initial velocity above this value, some of the rod will have melted, until the initial yield stress has decelerated the shank to below critical. The remainder of the 
deceleration will be normal. That is the rod will have lost mass from melting, and will also be deformed at the impact end.

We show the results of HEMP simulations for the case $\varepsilon_{1}=0.5, \varepsilon_{1}=2$, and $\mathrm{u}_{0} \cong 0.5 \mathrm{u}_{1}$. In the HEMP simulations, some localized melting does appear to occur below the critical velocity $\mathrm{u}_{1}$, although it does not extend to the lateral boundary.

We now assess the approximate value of $\varepsilon_{1}$ for the $\mathrm{Zr}$ alloy used in the experiments. The measured quasistatic flow stress $\mathrm{Y}_{0}$ is $20 \mathrm{~kb}$ [7]. If we take the room-temperature specific heat to be simple mixture of the atomic composition, $.066 \mathrm{cal} / \mathrm{g} /{ }^{\circ} \mathrm{C}$, then a temperature rise of $520^{\circ} \mathrm{C}$ corresponds to $\varepsilon_{1}=1$. Since the glass-temperature of this alloy is $350^{\circ} \mathrm{C}$ [8], we are assured that for this alloy $\varepsilon_{1}<1$.

\section{CONCLUSIONS}

The observations made during this study suggest that the Taylor test is not well suited to the evaluation of the dynamic yield strength of metallic glasses, particularly ones with glass transitions as low as the $\mathrm{Zr}$ alloy. Furthermore, we suggest caution in using the room temperature hardness or yield strength of metallic glasses as a criteria for a successful material to resist impact loading.

\section{ACKNOWLEDGMENTS}

The authors would like to thank Bruce Morgan for carrying out the gas gun experiments, and Dr. Ricardo Schwartz for providing property data on the metallic glass studied in this paper.

\section{REFERENCES}

[1] Taylor, G. I., Proc. Royal Soc. (London) A194 (1948) p. 289.

[2] Wilkins, M. L. and M. W. Guinan, J. Appl. Phys. 44 (1973) p. 1200.

[3] Cline, C.F. and Reaugh, J.E., "Dynamic yield strength of a paladium alloy metallic glass," $J$. de Physique III 1 (1991) p. 139.

[4] Steinberg, D. J., S. G. Cochran, and M. W. Guinan, "A constitutive model for metals applicable at high-strain rate," J. Appl. Phys 51 (3) (1980) pp. 1498-1504.

[5] Wilkins, M. L., in Methods of Computational Physics, B. Alder, S. Fernbach and M. Rotenberg, eds., Academic, NY 3 (1964) p. 211.

[6] Guinan, M. W., "B-Division annual report," LLNL (1971) (unpublished).

[7] Steinberg, D. J., S. G. Cochran and M. W. Guinan, J. Appl. Phys. 51 (1980) p. 1498.

[8] Davis, L. A. and S. Kavesh, J. Mat. Science 10 (1975) p. 453.

[9] Taub, A. I. and F. Spaepen, Scripta Metallurgica 14 (1980) p. 1197. 
Density, $p$

Glass transition temperature $(\mathrm{Tg})$

Crystallization temperature (Tc)

Debye temperature (from elastic constants)

$\mathrm{C}_{11}$

$\mathrm{C}_{44}$

Bulk modulus

Knoop microhardness @ 200 gm load

${ }^{*}$ At a heating rate of $5^{\circ} \mathrm{K} /$ minute
$6.10 \mathrm{gm} / \mathrm{cm}^{3}$

$623^{\circ} \mathrm{K}$

$693^{\circ} \mathrm{K}^{*}$

$327^{\circ} \mathrm{K}$

$162 \mathrm{GPa}$

$37.2 \mathrm{GPa}$

$112 \mathrm{GPa}$

$598 \mathrm{Kg} / \mathrm{mm}^{2}$

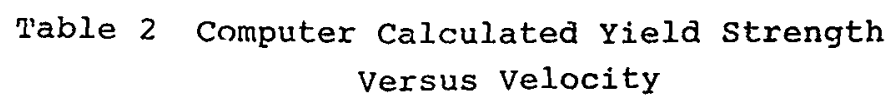

$\begin{array}{llll}\begin{array}{l}\text { Velocity } \\ \mathrm{km} / \mathrm{s}\end{array} & \text { Lf } & \text { Lf/Lo } & Y_{0}{ }^{*} \\ .01 & .948 & .988 & .025 \\ .015 & .899 & .936 & .010 \\ .02 & .869 & .905 & .012\end{array}$

"Yo calculated using relationships:

$$
Y_{0}=-\frac{\rho_{0} u_{0}{ }^{2}}{2 \ln L f / L_{0}}
$$




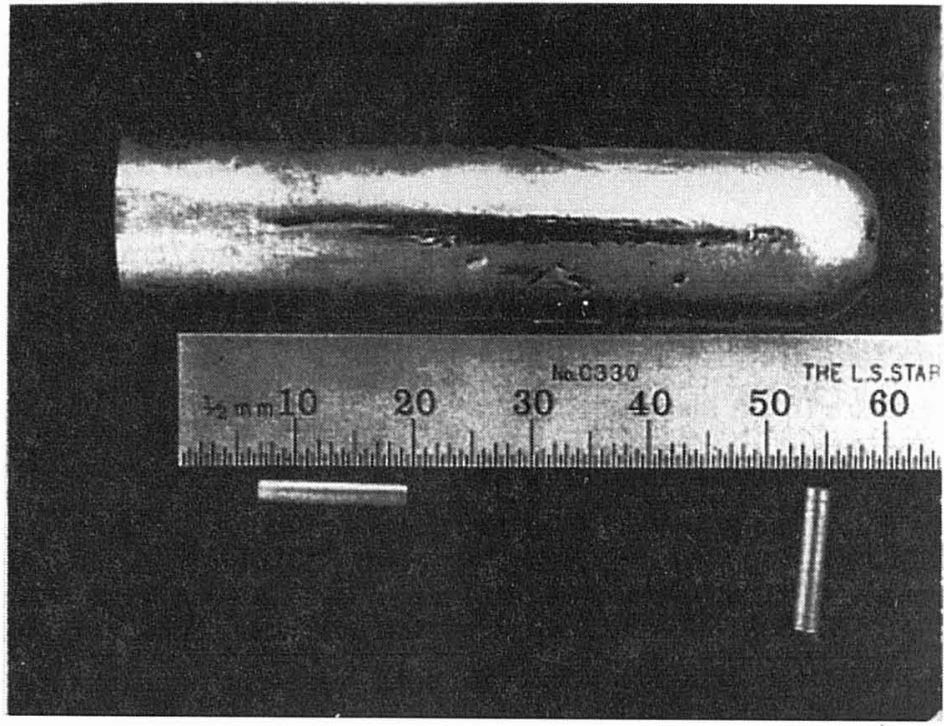

Figure 1. Photo of $\mathrm{Zr}$ base metallic glass ingot and projectiles.

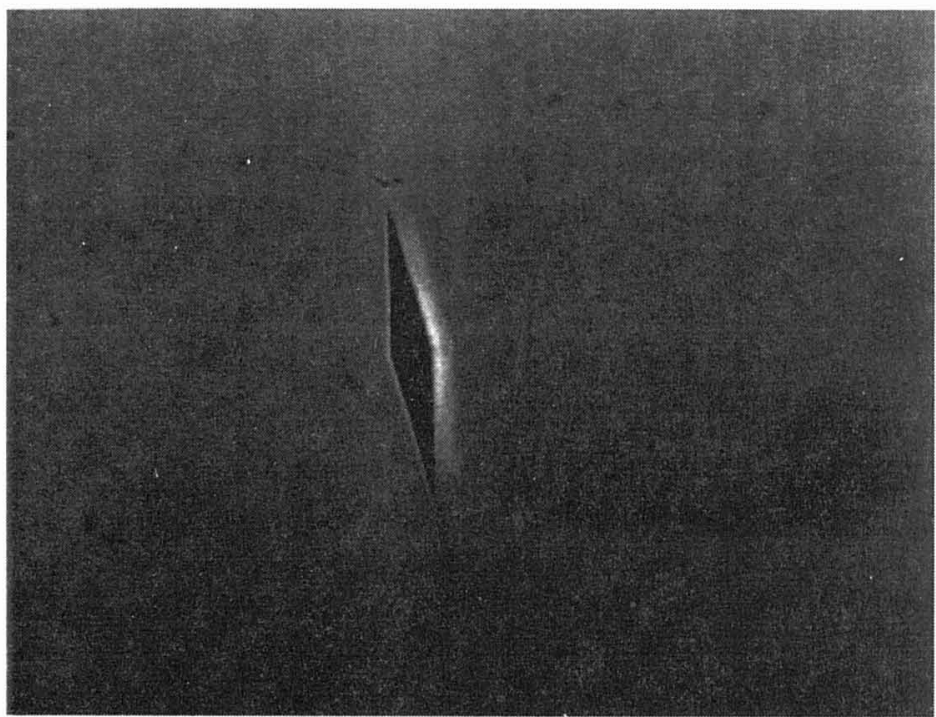

Figure 2. Knoop indentation into $\mathrm{Zr}$ metallic glass $200 \mathrm{gm}$ load $500 \mathrm{X}$ magnification. 